\title{
Researchers face delay in supplies of RU486
}

Washington. The politics of abortion in the United States is holding up clinical and preclinical research on RU486, the so-called 'abortion pill', which also promises many other biomedical applications in treatments ranging from breast cancer to brain tumours.

Earlier this year, faced with the heat surrounding the abortion debate, RousselUclaf, the manufacturers of the drug, handed over the US patent rights to the Population Council in New York. The council, a nonprofit group, has agreed to find a manufacturer and distributor in the United States and make the required New Drug Application to the Food and Drug Administration.

But the council - which has yet to name a manufacturer - will not have a stock of the drug for at least a year. Meanwhile, Roussel-Uclaf has stopped supplying the drug to new investigators. Supplies to existing trials, such as those for a type of brain tumour and the Population Council's abortion trials, will continue.

Wayne Bardin, director of the council's Center for Biomedical Research, has heard from about 20 investigators who have been affected by supply problems; some began writing to him in September to ask for supplies of the drug at the suggestion of RousselUclaf. Yet despite such demand, Andre Ulmann, director of research and development in endocrinology at Roussel-Uclaf, says the company will not be supplying RU486 to new investigators because of its contract with the Population Council.

One possible solution suggested by Bardin is for the Population Council to

\section{Changes urged in NIH peer review process}

Washington. The US National Institutes of Health (NIH) are being urged to appoint senior scientists to act as 'at large' members of its peer review committees.

The members would provide "a new measure of wisdom, perspective and continuity in the review process" says a report prepared by staff of NIH and Keith Yamamoto, head of the department of biochemistry and biophysics at the University of California, San Francisco and based on a meeting between NIH officials and researchers in September.

Since the arrival of Harold Varmus as NIH director, peer review - a key element in the distribution of the $\$ 8$ billion that the NIH spends annually on extramural research - has itself come under close scrutiny. Yamamoto is an active participant in debates on biomedical research policy and took part in an ad hoc meeting on peer review chaired by Varmus at NIH earlier this year (see Nature 369, 269; 1994).

The September meeting, which Yamamoto chaired, brought together for distribute the drug for Roussel-Uclaf until stocks are manufactured in the United States.

The current situation is the latest manifestation of the problems faced by US scientists interested in research with RU486. RU486 (mifepristone), is an antiprogestin, and it is important because although it binds progesterone receptors it has little progesterone-like activity. It prevents the progesterone effects needed to establish pregnancy, thereby causing abortion and it is this property that has created the political pressure to keep it out of the US.

But, as an antiprogestin, RU486 has much wider possible applications. In 1993, the US Institute of Medicine (IOM) released a report on the clinical applications of antiprogestins, describing them as having "a significant potential in human health". The institute cited the need to investigate the potential use of antiprogestins as a therapy for meningioma (a tumour of the membrane surrounding the brain), endometriosis, breast cancer and uterine leiomyomas (fibroids).

Mary Lake Polan, chair of the department of obstetrics and gynaecology at Stanford University in California, and a member of the committee that prepared the IOM report, says that in the current climate it is difficult to blame Roussel-Uclaf for wanting to keep RU486 at arms length.

Polan describes the IOM report as "an attempt to put RU486 back into the realm of science". But the move does not seem to

the first time NIH administrators from the review section responsible for the biological and physiological sciences with scientists who receive extramural grants.

The report recommends:

- An 'at large' member of review committees who would observe all study sections in a particular area of science, informing each of relevant developments in an area covered by a closely associated study section;

A broadening of expertise on study sections to help them to keep up with rapidly developing areas of research;

- Continuing scientific education for the NIH's scientific review administrators;

A relaxation of the rules defining the distribution of reviewers according to geographical areas or institutions, in order to ensure the best reviewers for the job can be selected;

- Further efforts to clarify the review process for applicants; and

- A continuing review of the scope and quality of peer review from different study sections.

\author{
IMAGE \\ UNAVAILABLE \\ FOR COPYRIGHT \\ REASONS
}

have succeeded. Several scientists failed to return repeated telephone calls from Nature. "You may have noticed [anti-abortionists are] shooting people," said one who did. "It's no longer a science issue, and it's hard to predict what people driven by a conviction of their own moral superiority will do."

One scientist who has repeatedly spoken out on the potential value of RU486 is Sam Yen, professor of reproductive medicine at the University of California, San Diego. "The emerging evidence is that this powerful new drug might have utility in the brain and the reproductive system," says Yen. "But these potential benefits are being deterred by politics." His own work was halted 18 months ago when he was caught up in a battle between Roussel-Uclaf and its German parent company Hoechst over whether to continue producing RU486. But he too is reluctant to blame the company when "their property might be burnt".

Yen has recently received a supply of RU486 through an informal international group of scientists. This source, however, is unable to meet all demands for the drug.

Canadian and European researchers are already evaluating RU486 for treating breast cancers. But the US National Cancer Institute has decided not to pursue research with this molecule. "We watch the literature, but for now we have many other promising therapies," says Michaele Christian, head of the National Cancer Institute's developmental chemotherapy section.

Another part of the US National Institutes of Health, the National Institute of Child Health and Human Development, has sponsored work at the Research Triangle Institute in North Carolina to develop an antiprogestin. Ed Cook, the head of the project, says it has a candidate compound but that it is a long way from being available for research with patients.

Roussel-Uclaf continues to face controversy, with both external and (it is said) internal pressures to abandon RU486 completely. Ulmann admits there are rumours that the company is pulling out of work on antiprogestins, but says that no such decision has been made.

Helen Gavaghan 